\title{
A Gray Patient
}

\author{
Gabriela Fortes Escobar ${ }^{1}$, Kelli Wagner Gomes ${ }^{2}$, Mariana Quirino Tubone ${ }^{3}$, \\ Gabriela Maldonado ${ }^{4}$
}

\author{
1 Department of Dermatology, Hospital de Clínicas de Porto Alegre, Porto Alegre, Brasil \\ 2 Private Practice - Rua Felipe Camarão 690/Sala 402, Porto Alegre, Brasil \\ 3 Private Practice - Av. Marcolino Martins Cabral, 2099/ Sala 902, Tubarão, Brasil \\ 4 Private Practice - Rua 24 de Outubro, 1440 /Sala 1103, Porto Alegre, Brasil
}

Citation: Escobar GF, Gomes KW, Tubone MQ, Maldonado G. A gray patient. Dermatol Pract Concept. 2022;12(1):e2022041. DOI: https://doi.org/10.5826/dpc.1201a41

Accepted: July 1, 2021; Published: January 2022

Copyright: (C2022 Escobar et al. This is an open-access article distributed under the terms of the Creative Commons Attribution-NonCommercial License (BY-NC-4.0), https://creativecommons.org/licenses/by-nc/4.0/, which permits unrestricted noncommercial use, distribution, and reproduction in any medium, provided the original authors and source are credited.

Funding: None.

Competing interests: None.

Authorship: All authors have contributed significantly to this publication.

Corresponding author: Gabriela Fortes Escobar, MD MSc Department of Dermatology, Hospital de Clínicas de Porto Alegre, Porto Alegre, Brasil. E-mail: gescobar@hcpa.edu.br

\section{Case Presentation}

A 46-year-old Caucasian woman presented with a 10 -year history of an asymptomatic progressive darkening of the skin. There was no previous history of inflammation, and she denied the use of medications. Examination revealed symmetric blue-gray patches involving the face, trunk (Figure 1, A and B) and extremities. Dermoscopy showed a diffuse reticulated-homogenous brown-gray pigmentation (Figure 1C). Skin biopsy revealed multiple spindle-shaped dendritic melanocytes in the dermis (Figure 1D) and immunohistochemical staining was positive for Melan-A and HMB-45.

\section{Teaching Point}

Acquired dermal melanocytosis is a rare pigmentary disorder and its etiology remains unknown. Three theories may explain this disorder: migration of epidermal melanocytes to the dermis; migration of hair bulb melanocytes; or reactivation of pre-existing latent dermal melanocytes triggered by local inflammation or an unknown stimulus [1,2]. Melanincontaining dendritic melanocytes can be seen in the uppermiddle portions of the dermis and, with the Tyndall effect, they result in a brown to bluish-gray skin pigmentation [2].

Informed consent: Written informed consent for publication of clinical details and clinical images was obtained from the patient. 


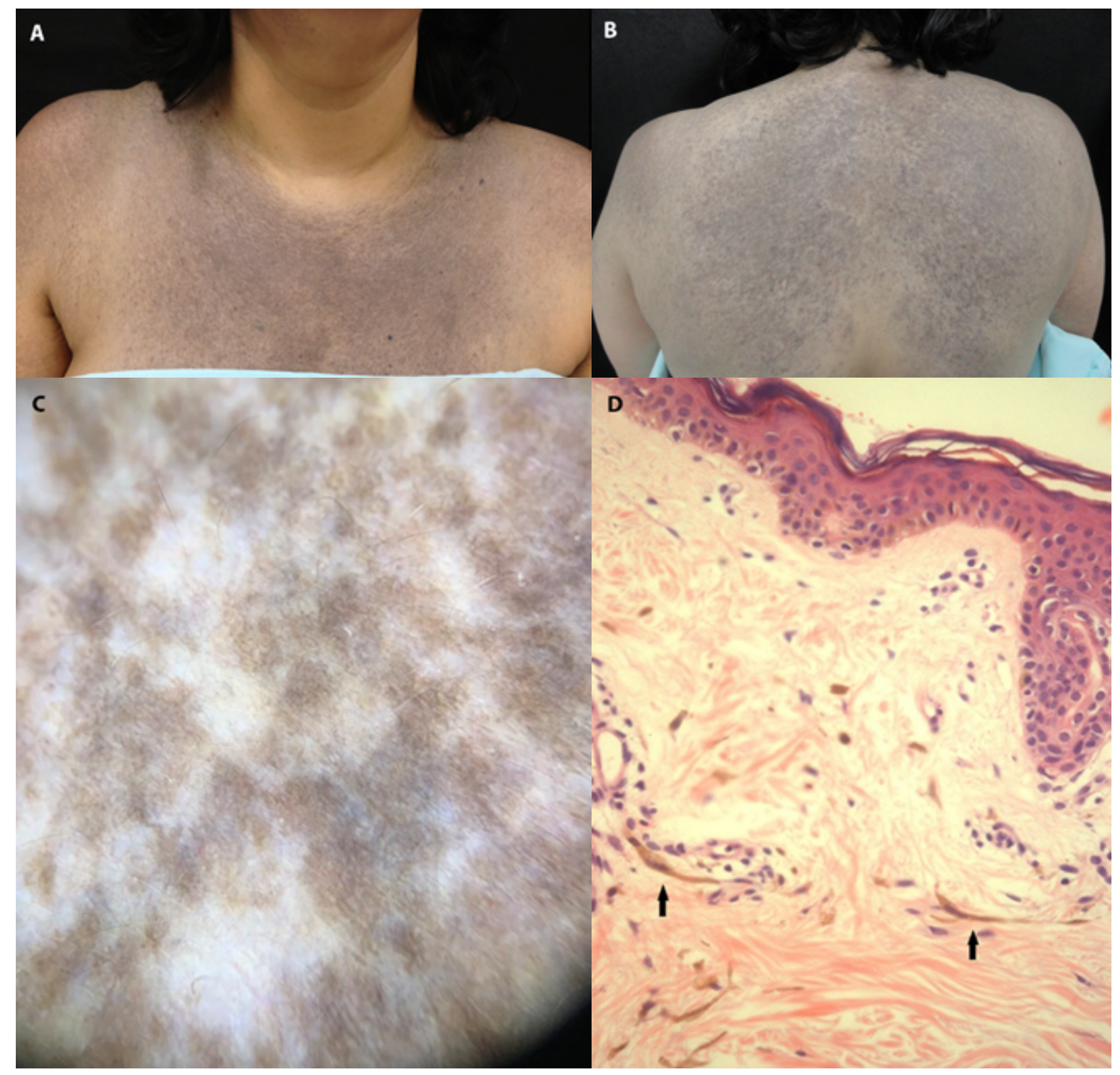

Figure 1. (A) and (B) Remarkable blue-gray pigmentation on the trunk. (C) Dermoscopy (10x) revealing a diffuse reticulated-homogenous brown-gray pigmentation. (D) Histopathology showing multiple spindle-shaped dendritic melanocytes in the dermis (arrows).

\section{References}

1. Harrison-Balestra C, Gugic D, Vincek V. Clinically distinct form of acquired dermal melanocytosis with review of published work. J Dermatol. 2007;34(3):178-182. DOI: 10.1111/j.13468138.2007.00245.x. PMID: 17291298.
2. Baykal C, Yılmaz Z, Sun GP, Büyükbabani N. The spectrum of benign dermal dendritic melanocytic proliferations. J Eur Acad Dermatol Venereol. 2019;33(6):1029-1041. DOI: 10.1111/ jdv.15492. PMID: 30767282. 